\title{
Combining simulation modeling and stable isotope analyses to reconstruct the last known movements of one of Nature's giants
}

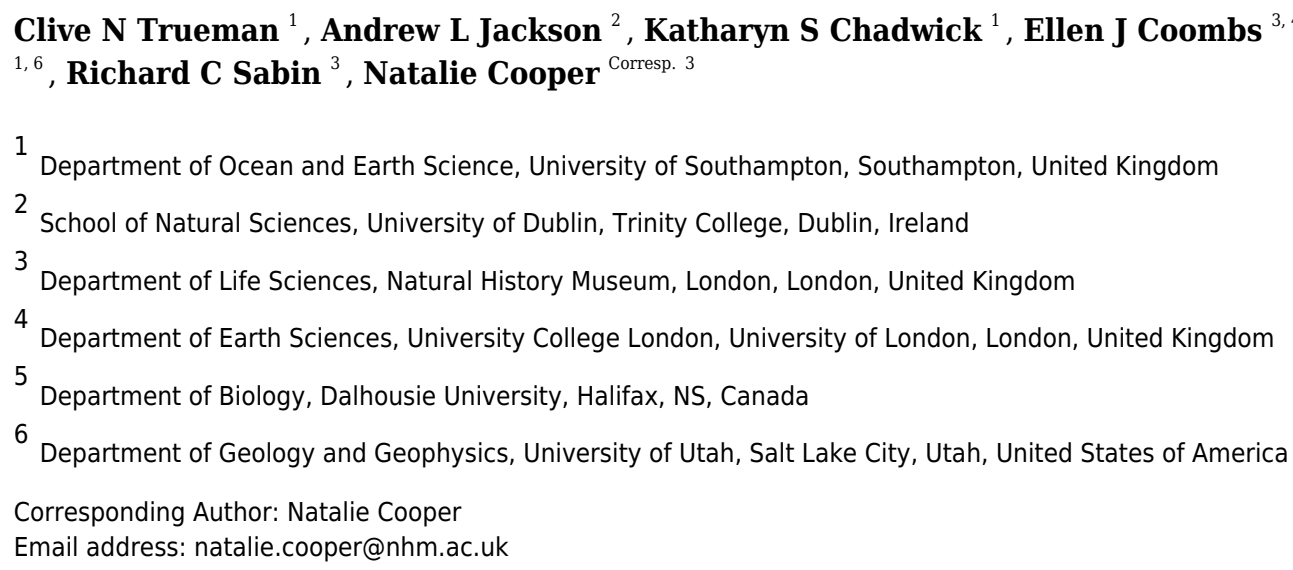

The spatial ecology of rare, migratory oceanic animals is difficult to study directly. Where incremental tissues are available, their chemical composition can provide valuable indirect observations of movement and diet. Interpreting the chemical record in incremental tissues can be highly uncertain, however, as multiple mechanisms interact to produce the observed data. Simulation modeling is one approach for considering alternative hypotheses in ecology and can be used to consider the relative likelihood of obtaining an observed record under different combinations of ecological and environmental processes. Here we show how a simulation modeling approach can help to infer movement behaviour based on stable carbon isotope profiles measured in incremental baleen tissues of a blue whale (Balaenoptera musculus). The life history of this particular specimen, which stranded in 1891 in the UK, was selected as a case study due to its cultural significance as part of a permanent display at the Natural History Museum, London. We specifically tested whether measured variations in stable isotope compositions across the analysed baleen plate were more consistent with residency or latitudinal migrations. The measured isotopic record was most closely reproduced with a period of residency in sub-tropical waters for at least a full year followed by three repeated annual migrations between sub-tropical and high latitude regions. The latitudinal migration cycle was interrupted in the year prior to stranding, potentially implying pregnancy and weaning, but isotopic data alone cannot test this hypothesis. Simulation methods can help reveal movement information coded in the biochemical compositions of incremental tissues such as those archived in historic collections, and provides context and inferences that are useful for retrospective studies of 
animal movement, especially where other sources of individual movement data are sparse or challenging to validate. 
1 Combining simulation modeling and stable isotope analyses to reconstruct the last known

2

3

4

5

6

$7 \quad{ }^{1}$ Department of Ocean and Earth Science, University of Southampton, Southampton, United

8 Kingdom.

$9{ }^{2}$ School of Natural Sciences, University of Dublin, Trinity College, Dublin, Ireland.

$10{ }^{3}$ Department of Life Sciences, Natural History Museum London, London, UK.

$11{ }^{4}$ Department of Earth Sciences, University College London, University of London, London, UK.

$12{ }^{5}$ Department of Biology, Dalhousie University, Halifax, Nova Scotia, Canada.

$13{ }^{6}$ Department of Geology and Geophysics, University of Utah, Salt Lake City, Utah, USA.

14

15

*Email address: natalie.cooper@nhm.ac.uk 


\section{Abstract}

19 The spatial ecology of rare, migratory oceanic animals is difficult to study directly. Where 20 incremental tissues are available, their chemical composition can provide valuable indirect

21 observations of movement and diet. Interpreting the chemical record in incremental tissues can

22 be highly uncertain, however, as multiple mechanisms interact to produce the observed data.

23 Simulation modeling is one approach for considering alternative hypotheses in ecology and can

24 be used to consider the relative likelihood of obtaining an observed record under different 25 combinations of ecological and environmental processes. Here we show how a simulation 26 modeling approach can help to infer movement behaviour based on stable carbon isotope 27 profiles measured in incremental baleen tissues of a blue whale (Balaenoptera musculus). The life history of this particular specimen, which stranded in 1891 in the UK, was selected as a case study due to its cultural significance as part of a permanent display at the Natural History Museum, London. We specifically tested whether measured variations in stable isotope compositions across the analysed baleen plate were more consistent with residency or latitudinal migrations. The measured isotopic record was most closely reproduced with a period

33 of residency in sub-tropical waters for at least a full year followed by three repeated annual migrations between sub-tropical and high latitude regions. The latitudinal migration cycle was interrupted in the year prior to stranding, potentially implying pregnancy and weaning, but isotopic data alone cannot test this hypothesis. Simulation methods can help reveal movement information coded in the biochemical compositions of incremental tissues such as those archived in historic collections, and provides context and inferences that are useful for retrospective studies of animal movement, especially where other sources of individual movement data are sparse or challenging to validate. 
42 Introduction

43 Migratory species pose a particular challenge for conservation practitioners because their

44 effective conservation relies on protection at many, often distant, sites (Runge et al. 2014).

45 Migratory species may also be particularly vulnerable to changes in climate or human use of the

46 environment, as they are influenced by conditions in multiple locations across different parts of

47 their life cycle (Robinson et al. 2009). Identifying threats to migratory species, understanding

48 species responses to global change and developing effective conservation measures all require

49 information on the movements of individual animals over multiple years, ideally for both

50 historic and present-day populations.

52 With the development of electronic tagging technology, studies of the distributions of animals

53 have been supplemented by detailed information about individual movement (Holdo \& Roach

54 2013), providing unprecedented levels of detail regarding individual movement behaviours and

55 potential environmental drivers for movement. However, despite the tremendous advances

56 made using direct telemetry devices, tags are expensive, difficult to deploy on large whales, and

57 rarely report information for longer than six months (Bailey et al. 2009; Best et al. 2015; Mate

58 et al. 2007). Data on individual-level, multi-annual movements remain scarce, especially for

59 dispersed, wide-ranging and long-lived marine species such as baleen whales (Mysticeti; Bailey

60 et al. 2009; Hall-Aspland et al. 2005; Ryan et al. 2013).

61

62 Natural tags, based on intrinsic biochemical information such as the stable isotope

63 compositions of tissues, provide an important additional tool for investigations of individual

64 animal movements (Busquets-Vass et al. 2017; Hobson \& Wassenaar, 2008; West et al. 2006).

65 Present-day populations can be studied with material collected in the field, while historic

66 populations can be studied using samples taken from museum collections; rich archives of

67 behavioral information that are often under-utilised (Lister et al. 2011). The stable isotope

68 composition of animal tissues reflects the isotopic composition of diet at the time and place of

Peer) reviewing PDF | (2019:01:34369:2:0:NEW 10 Sep 2019) 
69 ingestion, integrated over the timescale of tissue growth (Boeklen et al. 2011). However, 70 relating the isotopic compositions of marine animal tissues to the most likely location of tissue

71 growth is complicated by sources of uncertainty including spatial variation in the isotopic 72 composition of diet (the isotopic baseline; McMahon et al. 2015; West et al. 2006), and 73 numerous biochemical factors associated with the fractionation of stable isotopes between 74 predator tissues and prey (Boeklen et al. 2011; Newsome et al. 2010). This uncertainty is 75 compounded when multiple samples are taken through time in the same individual, as 76 temporal variation in the isotopic baseline, rates of movement of the consumer across isotopic gradients and growth rates of the sampled tissues must also be considered explicitly. The large number of uncertain variables complicates logic-based interpretation of sclerochemical data. Consequently, relatively little attention has been given to the potential to infer spatially-explicit individual movement histories from the isotopic compositions of sequentially sampled incrementally-grown tissues (Trueman \& St John Glew, 2019).

Considering multiple, non-exclusive alternative hypotheses rather than binary exclusive

83 hypotheses is recognized as an important but difficult barrier in scientific and ecological 84 reasoning (Betini et al. 2017). Simulation modeling is one tool that can be used to generate 85 predictions expected under multiple, user-defined hypothetical conditions. The results of 86 simulation models can be compared to observed data to identify which of a suite of hypotheses 87 are more consistent with observed data, and to determine the sensitivity of an observed 88 outcome to assumptions inherent in a method. Recently, mechanistic computational models 89 have been developed that provide isoscapes - relatively accurate predictions of isotopic variability at high temporal and spatial resolution. These models can be coupled to Lagrangian or agent-based models of animal movement to predict the range of isotopic compositions that could be recorded in animal tissues under differing movement scenarios (Carpenter-Kling et al. 2019; Darnaude et al. 2014; Sakamoto et al. 2019). measured in the baleen plate of a blue whale (Balaenoptera musculus). Mysticete whales are 
97 characterized by the development of baleen, keratinous structures in the upper jaw used to

98 filter food items from seawater. Baleen is ideal for stable isotope studies because keratin grows

99 continuously through an individual's life, and once laid down it is metabolically inert (Best \&

100 Schell, 1996; Hobson \& Schell, 1998). Baleen plates therefore offer a continuous isotopic record

101 of behavior typically reflecting multiple years of life of an individual whale. Baleen is worn away

102 at the tips over time, so a baleen plate reflects the most recent years of life, and rarely records

103 an individual's entire lifespan. Among the mysticete whales, blue whales are a particularly

104 attractive target for model-based isotope movement work as they have a consistent, low

105 trophic level diet and feed continuously through the year, likely driven by high energetic costs

106 of maintaining extreme muscle mass (Goldbogen et al. 2015).

108 Similar to other large balaenopterid whales, blue whales are generally assumed to conduct

109 annual migrations between high and low latitudes (Hucke-Gaete et al. 2018). Their migration

110 routes and feeding areas are thought to be shaped by highly productive regions (Branch et al.

111 2007), however, substantial individual variation in movement history and migration patterns

112 has been documented (Busquets-Vass et al. 2017). The northeast Atlantic population of blue

113 whales is estimated to be small - only 1000 individuals (Pike et al. 2009) - with foraging

114 observed around Iceland and historically in the Norwegian and Barents Seas in summer months

115 (Pike et al. 2009), and wintering in the upwelling systems between Mauritania and the Cape

116 Verde Islands (Baines \& Reichelt, 2014). Northward migrations may occur along mid Atlantic

117 corridors with peak sightings in the Azores in the spring (Silva et al. 2013), and southerly

118 migrating blue whales are frequently detected in waters to the west of the UK between

119 November and December (Baines et al. 2017; Charif \& Clark, 2009; Reeves et al. 2004; Visser et

120 al. 2011).

121

122 The movements of blue whales in the northeast Atlantic can be generalized from disparate

123 information sources but are poorly understood in detail. Movements of individual animals over

124 timescales of a year or more, the degree of connectivity between summer and winter feeding 
125 areas, and the level of temporal consistency in movement behaviour within individuals

126 represent large questions for understanding the ecology and life history of this species.

127 Identifying the historical movement patterns of individual blue whales is important for

128 understanding the current context of whale migrations, and potential for human-whale

129 conflicts as populations recover.

130

131 We aim to show that simulation modeling of stable carbon isotope tracers can be used to test

132 hypotheses about individual-level movement behavior. We specifically ask whether the

133 observed isotopic record is more consistent with migratory or resident behavior at annual

134 timescales. We draw on newly developed predictions of spatio-temporal variation in

135 phytoplankton and stable carbon isotope composition at global and monthly resolution (Figure

136 S1), and couple these with an agent-based model of idealized whale movement. By simulating

137 the carbon isotope record expected for several differing, plausible hypotheses of movement

138 behavior, we can assess the range of isotopic expression expected for each alternative

139 hypothesis. Modeled baleen isotope records associated with each movement scenario are

140 compared to the observations of carbon isotope variations found in the baleen of a culturally

141 significant blue whale, and illustrate a conceptual approach for interpreting the life history

142 information contained in incremental tissues. This study also provides new information and

143 understanding of the possible movements of an individual blue whale that lived in the North

144 Atlantic during the first era of industrial whaling.

\section{Materials and Methods}

\section{Stable isotope extractions from baleen}

147 Baleen was collected from a mature female blue whale, which stranded off the coast of

148 Wexford Ireland in March 1891. The whale "Hope" was estimated to be at least 15 years old

149 when she died and is currently on display in the Natural History Museum (NHM), London

150 (specimen NHMUK.1892.3.1.1). The specimen's baleen plate was cleaned with ethanol to

151 remove surface contaminants such as skin/gum or other lipids that can influence isotopic

152 signals. $1 \mathrm{mg}$ samples of keratin powder were then collected from the plate using a hand-held

Peer] reviewing PDF | (2019:01:34369:2:0:NEW 10 Sep 2019) 
153 drill and grinding bit. 97 samples were taken at $1 \mathrm{~cm}$ intervals, $0.5 \mathrm{~cm}$ from the outer edge of the

154 plate, starting at the proximal (gingival) section that contains the most recent tissue. Baleen is

155 assumed to grow at a relatively constant rate, so the samples are equally spaced through time

156 (Best \& Schell, 1996). Carbon and nitrogen isotope analysis was performed simultaneously via

157 continuous-flow isotope ratio mass spectrometry at the University of Southampton SEAPORT

158 Stable Isotope Ratio Mass Spectrometry Laboratory (Southampton, UK), using a Vario Isotope

159 select elemental analyser, coupled to an Isoprime 100 isotope mass spectrometer. Replicates

160 using internal laboratory standards (L-glutamic acid (C), Glutamic acid (CT standard), acetanilide

161 and protein standard OAS) were used for quality control and calibration. C: $N$ ratios for samples

162 ranged from 3.28 to 3.72, well within the acceptable theoretical range for pure keratin (

$1633.4 \pm 0.5$ ) allowing for comparison among samples (Hobson \& Schell, 1998). All data are

164 available from the NHM Data Portal (Trueman et al. 2018; https://doi.org/10.5519/0093278).

165

166 Time calibrating stable isotope profiles

167 Many mysticete whales are characterized by regular, seasonal variations in behavior with

168 increased feeding rates, typically in more productive higher latitudes in summer and reduced

169 feeding rates often in warmer waters in winter. The combination of movement across isotopic

170 gradients and physiological variations in feeding and excretion rates leads to marked, regular

171 cyclicity in baleen stable isotope data. Assuming such cyclicity represents annual seasonal

172 behavioural variations, the distance between successive isotopic peaks or troughs may indicate

173 the growth rate of the baleen (Schell et al. 1989; Best and Schell, 1996; Aguilar et al. 2014,

174 Busquets Vass et al. 2017). Accordingly, baleen growth rates have been estimated from

175 patterns of $\delta^{15} \mathrm{~N}$ cyclicity in fin whales (averaging $20 \mathrm{cmy}^{-1}$, Aguilar et al. 2014 ) and blue

176 whales (average growth rate estimated as $15.5 \pm 2.2 \mathrm{cmy}^{-1}$, Busquettes Vass et al 2017). We

177 quantified the periodicity of $\delta^{15} \mathrm{~N}$ fluctuations within Hope's baleen sample using Fourier

178 Transform analysis (periodogram function in the R package TSA; Chan \& Ripley, 2012; Cardona

179 et al. 2017; Figure S2), revealing an estimated growth rate of $13.5 \mathrm{cmy}^{-1}$, which is remarkably

180 similar to the mean isotope-derived baleen growth rates for blue whales from the East Pacific

Peer] reviewing PDF | (2019:01:34369:2:0:NEW 10 Sep 2019) 
181 of $15.5 \pm 2.2 \mathrm{cmy}^{-1}$ (Busquets-Vass et al, 2017). We assumed a date for the most recent 182 baleen sample as 1st March 1891, 24 days prior to the stranding date, 25th March 1891. Note 183 that we make an explicit assumption of continuous growth in baleen within the growth of the 184 individual, informed from the fluctuations in $\delta^{15} \mathrm{~N}$ values. The assumption of constant growth 185 (or the growth rate used) could be varied within a model simulation framework. We do not

186 draw on $\delta^{15} \mathrm{~N}$ values for any subsequent interpretations, avoiding conflating the signal used for 187 time calibration with additional inferences.

\section{Modeled isoscapes}

190 Isotope-enabled biogeochemical ocean models (Magozzi et al. 2017; Schmittner \& Somes, 191 2016) were used to characterize the isotopic composition of phytoplankton expected in 192 different potential foraging grounds (Figure S1). $\delta^{13} \mathrm{CPOM}$ values were simulated at $1^{\circ}$ and 193 monthly resolution using an isotopic extension to the NEMO-MEDUSA ocean biogeochemical 194 model (Magozzi et al. 2017; Yool et al. 2013). A full description of the carbon isotope model is 195 provided by Magozzi et al. (2017), but briefly $\delta^{13} \mathrm{C}$ POM values are estimated from modeled 196 growth rates of silica limited (diatom) and non-silica limited plankton, concentrations of 197 dissolved $\mathrm{CO}_{2}$ and estimated $\delta^{13} \mathrm{C}$ values of dissolved inorganic carbonate and $\mathrm{CO}_{2}$. We used 198 monthly simulated $\delta^{13} \mathrm{C}$ values drawn from output from the NEMO-MEDUSA model system 199 associated with climatological data from 2000-2010. As described in Magozzi et al. (2017), using 200 model outputs averaged across a decadal scales to drive isotopic estimates reduces the chance 201 of anomalous years influencing the predicted spatio-temporal patterns in phytoplankton $\delta^{13} \mathrm{C}$ 202 values. We assume that the broad oceanographic distribution of $\delta^{13}$ C POM values has 203 remained similar between 1890 and 2000. The addition of fossil fuel derived carbon to the 204 atmosphere and ocean has increased the concentration and reduced the $\delta^{13} \mathrm{C}$ values of 205 dissolved inorganic carbon and POM (the Suess effect; Young et al 2013). While absolute $\delta^{13} \mathrm{C}$ 206 values have reduced since pre-industrial times, here we assume that latitudinal and seasonal 207 variations in $\delta^{13} \mathrm{C}$ values have remained constant. We do not draw inferences about location 
208 from absolute $\delta^{13} \mathrm{C}$ values and thus the reduction in oceanic $\delta^{13} \mathrm{C}$ POM values does not directly

209 influence inferences about location or movement. We are therefore satisfied that the model

210 can be applied to interpret historic baleen isotope data at least at ocean-basin scale spatial

211 resolution, though we note that this is an assumption.

212

213 Annual average $\delta^{13} \mathrm{C}$ POM values largely vary with latitude, with lower values in more northerly

214 regions. In the central North Atlantic, $\delta^{13} \mathrm{C} \mathrm{POM}$ values are relatively high in the west, reflecting

215 warm gulf stream waters (Figure S1). The isotopic composition of carbon in phytoplankton also

216 varies through seasons as isotopic fractionation of carbon during photosynthesis is strongly

217 influenced by sea surface temperature (Laws et al. 1995; Magozzi et al. 2017). Thus temporal

218 variations in $\delta^{13} \mathrm{C}$ POM values are superimposed on latitudinal gradients. The scale and nature

219 of temporal variation in $\delta^{13} \mathrm{C}$ POM values also varies with latitude, with higher latitude seas

220 showing greater intra-annual variation in $\delta^{13} \mathrm{C}$ POM values linked to strongly seasonal

221 phytoplankton growth dynamics.

222

223 Agent-based whale movement model (hypothesis generation)

224 We simulated the likely isotopic expression associated with alternative movement hypotheses

225 by building an agent-based movement model in R (R Core Team 2018), where movement

226 behavior is influenced by sea surface temperature and phytoplankton biomass estimates

227 provided by NEMO-MEDUSA (Yool et al. 2013), and bathymetry from the General Bathymetric

228 Chart of the Oceans (GEBCO; Amante \& Eakins, 2009) extracted using the marmap R package

229 (Pante \& Simon-Bouhet, 2013; Figure S3).

230 We tested two main hypotheses: whether the whale was resident or migratory, and further

231 tested hypotheses associated with variation in the location of residency or starting location for

232 migratory whales. We coded whale movements with the likelihood, direction, and extent of

233 movement influenced by behavioral state, sea surface temperature, water depth, and

234 phytoplankton concentration (as a proxy for zooplankton food availability). Movement was

Peer] reviewing PDF | (2019:01:34369:2:0:NEW 10 Sep 2019) 
235 coded as a set of probabilistic rules, informed by the literature on blue whale behavior (e.g.

236 Wilson \& Mittermeier, 2014). All terms were expressed as probability distributions, yielding

237 multiple potential movement tracks.

239 In the models, at each daily time step the likelihood of moving, the direction (north, south, east, 240 west, northeast, northwest, southeast, or southwest) and the linear distance of movement are

241 all influenced by the following. (i) Behavioural state (migrating north, migrating south, or

242 foraging, fixed according to month as defined by the operator). Here, northerly migrations were 243 coded to occur in spring, and southerly migrations in autumn. Foraging was possible at any time 244 of year, and was triggered when whales encountered high concentrations of plankton. (ii) Sea 245 surface temperature $\left({ }^{\circ} \mathrm{C}\right)$. When migrating north, whales were more likely to move towards 246 lower temperatures provided they were above the minimum temperature threshold $\left(3^{\circ} \mathrm{C}\right)$, 247 whereas whales migrating south sought warmer waters. (iii) Water depth (m; from GEBCO; 248 Amante \& Eakins, 2009). Whales were less likely to move into waters less than 400m deep, and 249 increasingly unlikely to move into shallower waters. (iv) Phytoplankton concentration (mmolN

$250 \mathrm{~m}^{-3}$, for combined diatom and non-diatom communities; Yool et al. 2013). This was included 251 as a proxy for zooplankton food availability. Whales are more likely to move towards (or remain 252 within) areas of high phytoplankton density, particularly during the foraging behavioural state. 253 At each daily step, the probability of movement, movement direction and distance traveled are 254 sampled from probability distributions to allow individual variation.

256 Initial boundary conditions are defined with a maximum temperature of $25^{\circ} \mathrm{C}$ and minimum 257 temperature of $3^{\circ} \mathrm{C}$. The likelihood of movement (i.e. whether to move or not from the current 258 location) is sampled from a binomial distribution with the probability of movement influenced 259 by behavioural state and external conditions. The maximum daily movement distance 260 permitted in each behavioural state is defined as a random sample of a Gaussian distribution 261 with specified mean and standard deviation (see Table S1 and Figure S3). 
263 The agent-based model provides daily location data points that are then used to extract $\delta^{13} \mathrm{C}$

264 values from the isotopic extension to the NEMO-MEDUSA model and assembled to build

265 simulated isotopic profiles. We used $\delta^{13} \mathrm{C}$ POM values modeled at monthly resolution to

266 simulate the isotopic expression of phytoplankton expected to be encountered by whales

267 exhibiting differing movement behaviours. The stable isotope compositions of keratin at a given

268 point in the baleen will reflect the stable isotope compositions of the krill it was feeding on in

269 the weeks prior to keratin growth (as a best guess). Assimilation of carbon into krill tissues will

270 dampen the temporal variability seen in POM, effectively producing a temporal average over

271 the timescale of isotopic turnover within krill. We roughly assume the rate of assimilation of

272 phytoplankton biomass into krill to be complete between two and four months and therefore

273 we resampled the $\delta^{13} \mathrm{C}$ POM values in each one degree cell to reflect an average of isotopic

274 compositions in phytoplankton in the two months prior to the sampling date. Average values

275 were weighted according to the proportional plankton biomass estimated for each month.

276

277 Carbon isotope values are also likely to be altered during transfer from plankton to krill, as ${ }^{12} \mathrm{C}$ is

278 preferentially lost through respiration. The degree of such trophic fractionation is unclear,

279 however, and as we do not draw interpretations based on absolute $\delta^{13} \mathrm{C}$ values, rather on the

280 relative $\delta^{13} \mathrm{C}$ values across the length of the baleen plate, we do not need to quantify this

281 trophic enrichment effect. We assume that any trophic fractionation effect is constant in time

282 and space. We also assume that carbon available for synthesis of keratin is drawn from carbon

283 released by respiration of diet captured opportunistically throughout the year (Bailey et al.

284 2009; Baines et al. 2017; Branch et al. 2007, Busquets-Vass et al. 2017; Hucke-Gaete et al. 2018;

285 Lesage et al. 2017; Silva et al. 2013; Visser et al. 2011). For clarity, we chose to limit the number

286 of free variables in the current study, but the fixed assumptions associated with the temporal

287 lag between phytoplankton and baleen and trophic fractionation could be lifted and tested

288 within the simulation framework we describe. 
290 By manipulating the relative duration of the foraging and migratory behavioural states we

291 produced simulated records of isotopic compositions of carbon expected under differing

292 movement trajectories. We simulated the isotopic expression expected for (a) residency in each

293 known hotspot for blue whale sightings or historic hunting grounds in the North Atlantic

294 (Norwegian/Barents Sea, West Ireland, Canaries/Azores and Mid Atlantic Ridge, and the Cape

295 Verde/Mauritanian upwelling area (McDonald et al. 2006; Reilly et al. 2008; Sigurjónsson, 1995;

296 Figure S4); and (b) seasonal migration between high latitudes and subtropical latitudes. Within

297 each movement hypothesis simulation, individual whales were parameterized with random

298 variation in their maximum daily movement, providing a range of behaviours; a larger range of

299 maximum daily movement was introduced in migratory whales.

300 We simulated two years of residency 30 times for each residency hotspot (Figure S4). We

301 simulated seven years of whale movements 1200 times, then excluded simulations where the

302 virtual whale movement model failed (i.e. the simulated whale became 'trapped' in coastal

303 features) before reaching the 3019 days of the baleen record, leaving 1049 simulations. We

304 then compared the simulated stable isotope profiles (Figure 1) to the profile measured in the

305 blue whale baleen (Figure 2) with simple linear regressions.

306

307 R code for all analyses is available from GitHub (https://github.com/nhcooper123/blue-whale308 bes) 


\section{Results}

312 MODEL SIMULATION RESULTS

313 We initially simulated temporal variations in baseline (phytoplankton) isotopic compositions

314 that would be encountered by whales foraging within broad geographic regions

315 (Norwegian/Barents Sea, West Ireland, Canaries/Azores and Mid Atlantic Ridge, and the Cape

316 Verde/Mauritanian upwelling area Figure S4). Strong seasonal dynamics in $\delta^{13} \mathrm{C}$ values are

317 evident in northerly regions such as the Norwegian/Barents Sea, characterized by a rapid

318 increase to annual maximum $\delta^{13} \mathrm{C}$ values associated with the onset of the spring phytoplankton

319 bloom, followed by a more gradual decline in $\delta^{13} \mathrm{C}$ values towards minima in winter conditions

320 (Figure S4). In temperate latitudes west of the British Isles, seasonal dynamic cycles are present,

321 but dampened (Figure S4), whereas in sub-tropical regions exemplified by the Canaries, Mid

322 Atlantic and particularly Mauritanian upwelling areas, $\delta^{13} \mathrm{C}$ values are relatively high and

323 constant throughout the year (Figure S4).

324

325 Adding seasonal north-south migrations within mid-high latitude regions to foraging models

326 yielded simulated profiles with regular isotopic fluctuations of relatively high amplitude

327 reflecting $\delta^{13} \mathrm{C}$ minima preceding the June bloom (Figure S4, Figure 2).

\section{Atlantic whale baleen measured isotopic record}

330 The baleen plate yielded 97 discrete samples of baleen. $\delta^{15} \mathrm{~N}$ values measured in the baleen

331 plate display regular cyclical fluctuations throughout the length of the plate. Fourier analysis

332 (Cardona et al. 2017) revealed a strong periodic repetition with a $13.3 \mathrm{~cm}$ periodicity, with a

333 mean spacing of $13.5 \mathrm{~cm}$, assumed to represent annual periodicity. Therefore, given the date of

334 stranding (25th March 1891), and estimated baleen growth rates of $13.5 \mathrm{~cm} y^{-1}$, we

335 reconstructed a timeline for $\delta^{13} \mathrm{C}$ and $\delta^{15} \mathrm{~N}$ fluctuations in the baleen over seven full years of

336 the whale's life (early 1884 - spring 1891). 
$338 \delta^{13} \mathrm{C}$ values are relatively high and constant in the oldest (most distal) $35 \mathrm{~cm}$ of the baleen plate, 339 associated with a weakening of the periodic fluctuation seen in $\delta^{15} \mathrm{~N}$ values, and an overall 340 reduction in $\delta^{15} \mathrm{~N}$ values. This is followed by a clear change towards repeated fluctuations

341 in $\delta^{13} \mathrm{C}$ values in the middle $50 \mathrm{~cm}$ of the baleen plate, with a similar periodicity of $13.5 \mathrm{~cm}$ 342 (Figure 2; Figure S2). A second, distinct change in the pattern of $\delta^{13} \mathrm{C}$ values along the baleen 343 plate occurs at around $26 \mathrm{~cm}$ from the gingival end, with a transition to uniform, relatively low $344 \delta^{13} \mathrm{C}$ values followed by an abrupt transition to positive $\delta^{13} \mathrm{C}$ values and a decline in $\delta^{13} \mathrm{C}$ values 345 in the most recent (most gingival) $3 \mathrm{~cm}$ of the record.

346

347 The $\delta^{13} \mathrm{C}$ and $\delta^{15} \mathrm{~N}$ profiles therefore divide the isotopic record into three distinct phases that 348 we assume reflect changes in the whale's behaviour. In behavioural phase one (from the start 349 of the record to spring 1886), we find relatively stable, elevated $\delta^{13} \mathrm{C}$ values, and relatively low $350 \delta^{15} \mathrm{~N}$ values (Figure 2; Figures S2 and S5). In behavioural phase two (summer 1886 to spring 351 1890) $\delta^{15} \mathrm{~N}$ values are relatively high and $\delta^{13} \mathrm{C}$ values are relatively low with coincident cyclical 352 fluctuations in both $\delta^{13} \mathrm{C}$ and $\delta^{15} \mathrm{~N}$ values. In the last year of life the cyclical pattern is 353 disrupted, with constant low $\delta^{13} \mathrm{C}$ values for approximately six months in the first half of 1890, 354 before a rapid switch to relatively high $\delta^{13} \mathrm{C}$ values in the second half of 1890 . The final three 355 months of the record (behavioural phase three) show a progressive fall in $\delta^{13} \mathrm{C}$ values (Figure 2; 356 Figures S2 and S5). Cross-correlation analysis demonstrates a strong negative covariance 357 between $\delta^{13} \mathrm{C}$ and $\delta^{15} \mathrm{~N}$ values within behavioural phase two (Figure 2; Figure S5), but no 358 relationship between $\delta^{13} \mathrm{C}$ and $\delta^{15} \mathrm{~N}$ values exists during behavioural phase one. MODEL-MEASURED COMPARISON RESULTS

361 For each of the three behavioural phases identified within the baleen plate, the modeled 362 simulation results were compared to the observed stable isotope profile. In the observed 363 profile, behavioural phase one is characterised by relatively high and constant $\delta^{13} \mathrm{C}$ values. $\delta^{15}$ 
$364 \mathrm{~N}$ values in this phase are relatively low and the isotopic cyclicity is absent (Figure S2). The 365 relatively high and seasonally-invariant $\delta^{13} \mathrm{C}$ values seen during behavioural phase one were 366 reproduced only in simulations of whales resident in subtropical areas of the North Atlantic.

367 Our simulations identify a range of possible locations for the whale (Figure 3), although areas 368 around the Mauritanian coast and Cape Verde Islands, a known current and historic winter 369 feeding area for blue whales (Baines \& Reichelt, 2014; Reeves et al. 2004), and potentially to 370 the west of the Azores (Figure 3), most closely match the measured profile. Temporal dynamics 371 in $\delta^{13} \mathrm{C}$ values observed in the measured baleen during phase two cannot be reproduced in the 372 simulated resident whales (Figure 1, Figure S4). During behavioral phase two, the observed low $373 \delta^{13} \mathrm{C}$ values likely imply foraging in colder, more northerly latitudes.

375 To further examine this, we modeled 3.5 years of seasonal north-south migration in the 376 northeast northern Atlantic. We simulated 1200 individual movement patterns, and compared

377 the simulated baleen $\delta^{13} \mathrm{C}$ records of 1049 runs yielding full time series records to the 378 measured records with simple linear regressions. Simulated baleen $\delta^{13} \mathrm{C}$ profiles produce a 379 good fit to measured profiles, the median $r^{2}$ value across 1049 simulated profiles was 0.31, and 380 the maximum was 0.65 (Figure S6). The top $10 \%$ best fitting simulated profiles are shown in 381 Figure 3. Behavioral phase two is best simulated by seasonal migrations between summer 382 foraging in northern areas (e.g. Norwegian Sea/Barents Sea/Iceland region), and winter 383 foraging in a broad region between the UK and more southerly, subtropical waters. Better384 fitting models in general were those predicting a greater latitudinal foraging range, and foraging 385 in more northerly waters (Figures S7 and S8). Best-fit model distributions are largely consistent 386 with current understanding of blue whale distributions in the northeast Atlantic (Baines et al.

387 2017; Baines and Reichelt, 2014; Reeves et al. 2004), with perhaps greater importance of winter 388 foraging in temperate regions (Figure 4). 


\section{Discussion}

391 Long-term, multi-annual data on the movement patterns and reproductive ecology of individual

392 migratory marine animals are scarce. Stable isotope compositions of incrementally-grown

393 tissues provide a promising source of additional indirect information regarding spatio-temporal

394 behavior, but interpreting such profiles is difficult.

Here we show how numerical models can be used to simulate the temporal isotopic expressions expected within incrementally grown tissues associated with contrasting defined spatio-temporal foraging behaviours. We tested whether the isotopic variations observed across 6-7 years of growth of a baleen plate in a single blue whale in the northeast Atlantic could be better simulated by agent-based models coding for year round residency or latitudinal migration. The isotopic compositions in baleen from Hope showed three distinct phases. The isotopic variations measured during behavioural phase one could be simulated by year-round residency in relatively warm, sub-tropical waters with limited seasonal phytoplankton blooms.

404 The measured profile is therefore consistent with residency in warm sub-tropical waters for at 405 least one full year.

407 The measured isotopic variations seen in behavioural phase two, characterized by repeated 408 high amplitude cycles in $\delta^{13} \mathrm{C}$ values, were best matched by movement models coded to 409 produce annual latitudinal migrations, with best fitting models predicting greater latitudinal 410 foraging ranges. We therefore infer that Hope conducted at least three annual latitudinal 411 migration cycles.

413 Behavioral phase three, which covers the last 500 days of Hope's life, is difficult to simulate 414 purely from movements within the known geographic range. Beginning in the winter of

$4151889 / 1890$, the observed $\delta^{13} \mathrm{C}$ values are relatively low, and remain constant for c.4-6 months, 
416 before increasing rapidly in the second half of 1890. Low $\delta^{13} \mathrm{C}$ values are found in northern

417 waters, but these areas also show large temporal fluctuations in $\delta^{13} C_{\text {plk }}$ values (Figure S4) unlike

418 Hope's observed values. We suggest that the unusual $\delta^{13} \mathrm{C}$ record in the last period of life may

419 be associated with a change in health status such as pregnancy and calf rearing. Hope was

420 estimated to be at least 15 years old when she died (based on vertebral epiphyseal fusion; R.C.

421 Sabin pers.comm), so was probably older than 10 years old and therefore sexually mature

422 during this period, so this is a possibility.

424 Blue whales have a 10-12 month gestation period, with calving occurring in subtropical waters, 425 and calves are weaned after 6-7 months (Wilson \& Mittermeier, 2014). A period of fasting 426 associated with late pregnancy and nursing could result in release of lipid carbon reserves

427 assimilated from northern latitudes This would be consistent with Hope's constant, low $\delta^{13} \mathrm{C}$ 428 values. After c.4-6 months of low $\delta^{13} \mathrm{C}$ values, Hope has a period of relatively high $\delta^{13} \mathrm{C}$ values, 429 implying feeding in low latitude waters consistent with warmer calving grounds, shortly 430 followed by a final northward migration before she died. We stress that bulk protein $\delta^{13} \mathrm{C}$ 431 values alone cannot definitively identify changes in metabolic pathways associated with fasting 432 or pregnancy.

434 In summary, our combined isotopic measurements and simulations allow us to propose a 435 movement history for the last 5-6 years of Hope's life. Behavioural phase one lasting for at least 436 a year, most likely reflects residency in sub-tropical waters, potentially in the Cape Verde, 437 Canary current region. Subsequently, in behavioural phase two, we infer that Hope conducted 438 three uninterrupted annual latitudinal migrations, wintering in sub-tropical waters and moving 439 to sub-arctic waters during late spring and summer. finally, in behavioural phase three, we 440 tentatively suggest that Hope may have given birth in the winter of 1889/1890. Following 441 which, we infer a period of c.4-6 months of residency in sub-tropical waters where Hope was 442 sustained largely from stored lipid reserves. Finally we propose that Hope had a short period of 
443 feeding in sub-tropical waters in the second half of 1890 potentially during a final northward 444 migration and eventual stranding during the return to northern feeding grounds in early 1891.

446 Our approach is relatively simple and we stress that comparisons between simulated and 447 measured datasets face several limitations. Critically, the likely accuracy of any simulation is 448 only as good as the underlying numerical isotope model(s). In our case we used an isotopic 449 extension to the NEMO-Medusa biogeochemical model system. Our model captures broad geographic and temporal variations in carbon isotopic compositions of phytoplankton (Magozzi et al. 2017), but may underestimate temporal variability associated with local features such as

452 frontal systems, eddies or coastal processes. Furthermore the model is not parameterized for 453 specific years: rather we draw on decadal climatological average output. It is possible that 454 spatio-temporal variations in phytoplankton compositions simulated for the start of the $21^{\text {st }}$ 455 century do not effectively capture conditions at the end of the $19^{\text {th }}$ century. However, we 456 restrict our interpretations to broad comparisons such as whether measured data are better 457 simulated by residency or latitudinal migrations, and at such broad scales we suspect that 458 temporal variations in the spatio-temporal distributions of $\delta^{13} \mathrm{C}$ values are a relatively minor 459 source of variance. It would of course be possible to run simulations using hindcast isotope 460 models parameterized for conditions expected in the late $19^{\text {th }}$ century.

462 A second source of uncertainty lies in the isotopic effects of trophic transfer from 463 phytoplankton to zooplankton prey and ultimately whale baleen. These transfer effects include 464 temporal averaging and physiological effects associated with respiration and assimilation of 465 proteins compared to lipids. We did not include physiological models in our simulations other 466 than adding temporal averaging to phytoplankton $\delta^{13} \mathrm{C}$ values, and a fixed correction term 467 between phytoplankton and baleen. The amplitude of isotopic variability varies widely between 468 simulated and measured baleen values; with higher amplitude effects in simulated 469 phytoplankton $\delta^{13} \mathrm{C}$ values. It is possible that isotopic dampening or signal attenuation reflects 
470 partial homogenization of $\delta^{13} \mathrm{C}$ values through physiological mixing of carbon assimilated at

471 different times (tissue turnover) within whale body fluids. The simulation framework provides a

472 methodology to explore hypotheses related to the effects of temporal averaging and

473 preferential nutrient acquisition. We note, however, that in many simulation model

474 approaches, complexity comes at the cost of transparency. In this case study we chose to limit

475 model complexity, demonstrating the extent to which measured profiles could be reproduced

476 using relatively simple transfer functions between simulated phytoplankton $\delta^{13} \mathrm{C}$ values and

477 whale baleen.

478

479

Whaling was an intense pressure for blue whales during the period we are analyzing (Reilly et

480

al. 2008). While we are inferring spatio-temporal distributions of just one individual, our study

481

demonstrates a method for inferring historical distributions and movement patterns for a

482

species that was heavily depleted and is only now returning from the brink of extinction in the

483

north Atlantic. In the case of blue whales, the primary driver influencing seasonal movements is

484

assumed to be the seasonally variable distribution of food resources between high and low

485

latitudes. Although ecological drivers of movement were not the focus of this study, we expect

486

due to metabolic requirements that blue whales have a distribution that is tightly coupled to

487

predictable spatio-temporal differences in prey abundance on ocean basin scales (Holdo \&

488

Roach, 2013). We suggest that the seasonal latitudinal migrations inferred during Hope's

489

behavioural phase two are also likely to be a common movement pattern for north Atlantic

490

blue whales, but the inference of sustained residency in sub-tropical waters might suggest

491

plasticity in individual movement behaviours. In future, additional isotopic records from

492

individual blue whales, observational sightings data, and multi-year satellite tracking records

493 will allow us to test the generality of this pattern for historical and contemporary populations.

494 Developing an understanding of the nature and plasticity of individual-level movements across

495 populations of large whales would improve our understanding of their population structure and

496 could assist spatially-based management decisions affecting the conservation of endangered

497 marine species like blue whales (Irvine et al. 2017).

Peer] reviewing PDF | (2019:01:34369:2:0:NEW 10 Sep 2019) 
Conclusion

500 Temporal variations in stable isotope compositions of incrementally grown tissues offer a 501 potentially valuable record of movement in migratory organisms, but interpreting these profiles

502 is extremely difficult, particularly in marine environments. Here we show how a simulation 503 framework can be used to help interpret measured data through in silico experimentation. By 504 varying parameters of agent-based movement models coupled to models predicting temporal 505 and spatial variation in plankton carbon isotope data we identify combinations of movement 506 behaviours producing simulated baleen isotope records that are most consistent with 507 measured data.

508

509 Our results confirm that sequential sampling of stable isotope compositions in whale baleen, 510 combined with simulation modeling can yield plausible inferences of individual whale 511 movements that are consistent with assumed movement behaviours, provided our various 512 model assumptions are true. Our movement simulation modeling removes a long-standing 513 limitation in stable isotope ecology, and can be applied to stable isotope records from any 514 incrementally-grown tissue (e.g. baleen, pinniped vibrissae, otoliths, vertebrae, eye lenses,

515 teeth and long bones) to estimate individual movement behaviors over multiple years. By 516 unlocking information contained in incrementally-grown tissues we hope that a more detailed 517 picture of individual movement behaviour in modern and historic specimens of marine species 518 can be developed.

\section{Acknowledgments}

521 We thank C.J. Somes for providing $\delta^{15} \mathrm{~N}$ POM data, Bastian Hambach and Megan Spencer at the 522 University of Southampton SEAPORT isotope laboratory for assistance with stable isotope 
523 analyses, Andrew Yool for allowing us to use and share NEMO-MEDUSA outputs, and Sam

524 Rossman and multiple anonymous reviewers for comments on earlier versions.

525

\section{Data Code and Materials}

527 Data are available from the NHM Data Portal (https://doi.org/10.5519/0093278). R code is

528 available from GitHub (https://github.com/nhcooper123/blue-whale-bes; DOI:

529 10.5281/zenodo.2542777).

530

531

\section{References}

532 Aguilar, A., Giménez, J., Gómez-Campos, E., Cardona, L. \& Borrel, A. 2014. $]^{15} \mathrm{~N}$ value does not 533 reflect fasting in mysticetes. PLoS ONE 9(3): e92288.

534

535 Amante, C. \& Eakins, B. 2009. Etopo1 1 arc-minute global relief model: Procedures, data

536 sources and analysis. NOAA Technical Memorandum NESDIS NGDC-24. National Geophysical

537 Data Center, NOAA. doi:10.7289/V5C8276M [Accessed 10th Nov 2017].

538

539 Bailey, H., Mate, B. R., Palacios, D. M., Irvine, L., Bograd, S. J., \& Costa, D. P. 2009. Behavioural 540 estimation of blue whale movements in the northeast Pacific from state-space model analysis

541 of satellite tracks. Endanger. Spec. Res., 10, 1-1.

542

543 Baines, M., Reichelt, M. \& Griffin, D. 2017. An autumn aggregation of fin (Balaenoptera

544 physalus) and blue whales (B. musculus) in the porcupine seabight, southwest of Ireland. Deep

545 Sea Research Part II: Topical Studies in Oceanography.

546

547 Baines, M. E. \& Reichelt, M. 2014. Upwellings, canyons and whales: An important winter habitat

548 for balaenopterid whales off Mauritania, northwest Africa. J. Cet. Res. Man., 14, 57-67. 
550 Best, P. \& Schell, D. 1996. Stable isotopes in southern right whale (Eubalaena australis) baleen

551 as indicators of seasonal movements, feeding and growth. Marine Biol., 124, 483-494.

552

553 Best, P. B., Mate, B. \& Lagerquist, B. 2015. Tag retention, wound healing, and subsequent

554 reproductive history of southern right whales following satellite-tagging. Marine Mamm. Sci., $55531,520-539$.

556

557 Betini, G.S., Avgar, T., Fryxell, J.M. 2017. Why are we not evaluating multiple competing 558 hypotheses in ecology and evolution? Roy. Soc. Open Sci., 4, 160756.

559

560 Boeklen, W.J., Yarnes, C.T., Cook, B.A., James, A.C. 2011 On the use of stable isotopes in trophic 561 ecology. Ann. Rev. Ecol. Evol. Syst., 42, 411-440.

562

563 Branch, T. A., Stafford, K. M., Palacios, D. M., Allison, C., Bannister, J. L., Burton, C. L. K., 564 Cabrera, E., Carlson, C. A., Galletti Vernazzani, B., Gill, P. C., Hucke-Gaete, R. R., Jenner, K.C. S., 565 Jenner, M.-N. M., Matsuoka, K., Mikhalev, Y. A., Miyashita, T., Morrice, M. G., Nishiwaki, S., 566 Sturrock, V. J., Tormosov, D., Anderson, R. C., Baker, A. N., Best, P. B., Borsa, P., Bronwell Jr, R. 567 L., Childerhouse, S., Findlay, K. P., Gerrodette, T., Ilangakoon, A. D., Joergensen, M., Kahn, B., 568 Ljungblad, D. K., Maughan, B., McCauley, R. D., McKay, S., Norris, T. F., , Rankin, S., Samaran, F., 569 Thiele, D., van Waerebeek, K. \& Warneke, R. M. 2007. Past and present distribution, densities 570 and movements of blue whales Balaenoptera musculus in the southern hemisphere and 571 northern Indian ocean. Mamm. Rev., 37, 116-175.

572

573 Busquets-Vass, G., Newsome, S. D., Calambokidis, J., Serra-Valente, G., Jacobsen, J. K., Aguíñiga-

574 García, S. \& Gendron, D. 2017. Estimating blue whale skin isotopic incorporation rates and 575 baleen growth rates: Implications for assessing diet and movement patterns in mysticetes. PLoS 576 ONE, 12, e0177880. 
578 Cardona, L., Vales, D., Aguilar, A., Crespo, E. \& Zenteno, L. 2017. Temporal variability in stable

579 isotope ratios of $\mathrm{C}$ and $\mathrm{N}$ in the vibrissa of captive and wild adult South American sea lions

580 Otaria byronia: More than just diet shifts. Marine Mamm. Sci., 4, 975-990.

581

582 Carpenter-Kling, T., Pistorius, P., Connan, M., Reisinger, R., Magozzi, S., \& Trueman, C. 2019.

583 Sensitivity of $\delta^{13} \mathrm{C}$ values of seabird tissues to combined temporal, spatial and ecological

584 drivers: A simulation approach. J. Exp. Biol. Ecol., 512, 12-21.

585

586

Darnaude, A.M., Sturrock, A., Trueman, C.N., Mouillot, D., Campana, S.E. \& Hunter, E. 2014.

Listening in on the past: What can otolith $\mathrm{d} 180$ values really tell us about the environmental

588 history of fishes? PLoS ONE, 9, e108539

589

590

Chan, K.-S. \& Ripley, B. 2012. TSA: Time Series Analysis. R package version 1.01.

591

592 Charif, R. A. \& Clark, C. W. 2009. Acoustic monitoring of large whales in deep waters north and 593 west of the British Isles: 1996-2005. Cornell Laboratory of Ornithology Bioacoustics Research 594 Program Technical Reports, 08-07.

595

596 Goldbogen, J. A., Hazen, E. L., Friedlaender, A. S., Calambokidis, J., DeRuiter, S. D., Stimpert, A.

597 K. \& Southall, B. L. 2015. Prey density and distribution drive the three-dimensional foraging 598 strategies of the largest filter feeder. Functional Ecology, 29, 951-961.

599

600 Hall-Aspland, S. A., Rogers, T. L. \& Canfield, R. B. 2005. Stable carbon and nitrogen isotope 601 analysis reveals seasonal variation in the diet of leopard seals. Marine Ecol. Prog. Ser., 305, 602 249-259.

603

604 Hobson, K. A. \& Schell, D. M. 1998. Stable carbon and nitrogen isotope patterns in baleen from 
605 606

607 608 609

eastern arctic bowhead whales (Balaena mysticetus). Can. J. Fish. Aq. Sci., 55, 2601-2607.

Hobson, K. A. \& Wassenaar, L. I. (eds.). 2008. Tracking Animal Migration with Stable Isotopes. Academic Press; 29

Holdo, R. M. \& Roach, R. R. 2013. Inferring animal population distributions from individual tracking data: theoretical insights and potential pitfalls. J. Anim. Ecol., 82, 175-181.

Hucke-Gaete, R., Bedriñana-Romano, L., Viddi, F., Ruiz, J., Torres-Florez, J. \& Zerbini, A. 2018.

From Chilean Patagonia to Galapagos, Ecuador: novel insights on blue whale migratory pathways along the eastern South Pacific. PeerJ, 6, e4695.

Irvine, L. G., Thums, M., Hanson, C. E., McMahon, C. R. \& Hindell, M. A. 2017. Quantifying the energy stores of capital breeding humpback whales and income breeding sperm whales using historical whaling records. Roy. Soc. Open Sci., 4, 160290.

Laws, E. A., Popp, B. N., Bidigare, R. R., Kennicutt, M. C. \& Macko, S. A. 1995. Dependence of phytoplankton carbon isotopic composition on growth rate and $\left[\mathrm{CO}_{2}\right]$ aq: Theoretical considerations and experimental results. Geochim. Cosmochim. Acta, 59, 1131-1138.

Lesage, V., Gavrilchuk, K., Andrews, R. D. \& Sears, R. 2017. Foraging areas, migratory movements and winter destinations of blue whales from the western North Atlantic. Endanger. Spec. Res., 34, 27-43.

Lister, A. M., \& Climate Change Research Group. 2011. Natural history collections as sources of long-term datasets. Trends Ecol. Evol., 26, 153-154.

Magozzi, S., Yool, A., Vander Zanden, H., Wunder, M. \& Trueman, C. 2017. Using ocean models to predict spatial and temporal variation in marine carbon isotopes. Ecosphere, 8, e01763. 
634

635 Mate, B., Mesecar, R. \& Lagerquist, B. 2007. The evolution of satellite-monitored radio tags for

636 large whales: One laboratory's experience. Deep Sea Research Part II: Topical Studies in

637 Oceanography, 54, 224-247.

638

639

McDonald, M. A., Mesnick, S. L. \& Hildebrand, J. A. 2006. Biogeographic characterization of blue 640 whale song worldwide: using song to identify populations. J. Cet. Res. Man., 8, 55-65.

641

642

McMahon, K. W., McCarthy, M. D., Sherwood, O. A., Larsen, T. \& Guilderson, T. P. 2015.

643 Millennial-scale plankton regime shifts in the subtropical north Pacific ocean. Science, 350, 644 1530-1533.

645

646

Newsome, S.D., Clementz, M.T. \& Kock, P.L. 2010. Using stable isotope biogeochemistry to 647 study marine mammal ecology. Marine Mamm. Sci., 26, 509-572.

648

649

Pante, E. \& Simon-Bouhet, B. 2013. marmap: A package for importing, plotting and analyzing

650 bathymetric and topographic data in R. PLoS ONE, 8, e73051.

651 Doi:10.1371/journal.pone.0073051.

652

653 Pike, D. G., Víkingsson, G. A., Gunnlaugsson, T. \& Øien, N. 2009. A note on the distribution and 654 abundance of blue whales (Balaenoptera musculus) in the central and northeast North Atlantic. 655 NAMMCO Scientific Publications, 7, 19-29.

656

657 R Core Team. 2018. R: A language and environment for statistical computing. R Foundation for 658 Statistical Computing, Vienna, Austria.

659

660 Reeves, R. R., Smith, T. D., Josephson, E. A., Clapham, P. J. \& Woolmer, G. 2004. Historical 661 observations of humpback and blue whales in the North Atlantic ocean: Clues to migratory 662 routes and possibly additional feeding grounds. Marine Mamm. Sci., 20, 774-786. 
663

664 Reilly, S., Bannister, J., Best, P., Brown, M., Brownell Jr, R., Butterworth, D., Clapham, P., Cooke, 665 J., Donovan, G., \& Urbán, J. 2008. IUCN Red List of Threatened Species, chapter Balaenoptera 666 musculus. IUCN, Gland, Switzerland.

667

668 Robinson, R. A., Crick, H. Q., Learmonth, J. A., Maclean, I., Thomas, C. D., Bairlein, F., 669 Forchhammer, M. C., Francis, C. M., Gill, J. A., Godley, B. J., Harwood, J., Hays, G.C., Huntley, B., 670 Hutson, A.M., Pierce, G.J., Rehfisch, M.M., Sims, D.W., Santos, M.B., Sparks, T.H., Stroud, D.A. \& 671 Visser, M.E. 2009. Travelling through a warming world: climate change and migratory species. 672 Endanger. Spec. Res., 7, 87-99.

673

674 Runge, C. A., Martin, T. G., Possingham, H. P., Willis, S. G. \& Fuller, R. A. 2014. Conserving 675 mobile species. Front. Ecol. Environ., 12, 395-402.

676

677 Ryan, C., McHugh, B., Trueman, C. N., Sabin, R., Deaville, R., Harrod, C., Berrow, S. D., \& 678 O'Connor, I. 2013. Stable isotope analysis of baleen reveals resource partitioning among 679 sympatric rorquals and population structure in fin whales. Marine Ecol. Prog. Ser., 479, 251680261.

681

682 Sakamoto, T., Komatsu, K., Shirai, K., Higuchi, T., Ishimura, T., Setou, T., Kamimura, Y., 683 Watanabe, C., \& Kawabata A. 2019. Combining microvolume isotope analysis and numerical 684 simulation to reproduce fish migration history. Methods Ecol. Evol., 10, 59-69.

685

686

Schell, D.M., Saupe, S.M. \& Haubenstock, N. 1989. Bowhead whale (Balaena mysticetus) growth 687 and feeding as estimated by $~^{13}{ }^{13} \mathrm{C}$ techniques. Mar. Biol. 103: 433-443.

688

689 Schmittner, A. \& Somes, C. J. 2016. Complementary constraints from carbon (13C) and nitrogen $690(15 N)$ isotopes on the glacial ocean's soft-tissue biological pump. Paleoceanography, 31, 669691693. 
692

693 Sigurjónsson, J. 1995. On the life history and autecology of North Atlantic rorquals. Devel. in

694 Marine Biol., 4, 425-441.

695

696 Silva, M. A., Prieto, R., Jonsen, I., Baumgartner, M. F. \& Santos, R. S. 2013. North Atlantic blue

697 and fin whales suspend their spring migration to forage in middle latitudes: building up energy

698 reserves for the journey? PLoS ONE, 8, e76507.

699

700 Trueman, C.N., Jackson, A.L., Chadwick, K., Coombs, E., Magozzi, S., Sabin, R. \& Cooper, N. 2018.

701 Dataset: Baleen stable isotope data. Natural History Museum Data Portal (data.nhm.ac.uk).

702 https://doi.org/10.5519/0093278.

703

704 Trueman, C.N., Jackson, A.L. \& Cooper, N. 2019. GitHub: nhcooper123/blue-whale-bes v1.0.

705 zenodo. https://doi.org/10.5281/zenodo.2542777.

706

707 Trueman, C.N, \& St John Glew, K. 2019. Isotopic tracking of marine animal movement. In:

708 Tracking Animal Migration with Stable Isotopes. Academic Press, 137-172.

709

710 Visser, F., Hartman, K. L., Pierce, G. J., Valavanis, V. D. \& Huisman, J. 2011. Timing of migratory

711 baleen whales at the Azores in relation to the North Atlantic spring bloom. Marine Ecol. Prog.

712 Ser., 440, 267-279.

713

714 West, J. B., Bowen, G. J., Cerling, T. E. \& Ehleringer, J. R. 2006. Stable isotopes as one of nature's 715 ecological recorders. Trends Ecol. Evol., 21, 408-414.

716

717 Wilson, D. \& Mittermeier, R. (eds.). 2014. Handbook of Mammals of the World. 4: Sea

718 Mammals. Lynx Edicions, Barcelona, Spain.

719

720 Yool, A., Popova, E. \& Anderson, T. 2013. Medusa-2.0: an intermediate complexity 
721 biogeochemical model of the marine carbon cycle for climate change and ocean acidification 722 studies. Geosci. Model Devel., 6, 1767-1811.

723

724 Young, J.N., Bruggeman, J., Rickaby, R.E.M., Erez, J. \& Conte, M. 2013. Evidence for changes in

725 carbon isotopic fractionation by phytoplankton between 1960 and 2010. Global Biogeochemical

726 Cycles 27: 505-515.

727 
Figure 1

Correlations among simulated $\mathrm{d} 13 \mathrm{C}$ from the top $10 \%$ best fitting migratory movement models and and $\mathrm{d} 13 \mathrm{C}$ from baleen.

Correlations among simulated $\mathrm{d} 13 \mathrm{C}$ from the top $10 \%$ best fitting migratory movement models (grey lines, right hand y-axis) and d13C from baleen (black line, left hand y-axis; see Figure 2). Simulated d13C values are six month moving average values for the time series of simulated plankton d $13 \mathrm{C}$ values in that location, reflecting temporal integration of phytoplankton $\mathrm{d} 13 \mathrm{C}$ values within the food chain before ingestion by the whale as krill. The end points of the simulations and empirical data have been aligned to coincide.

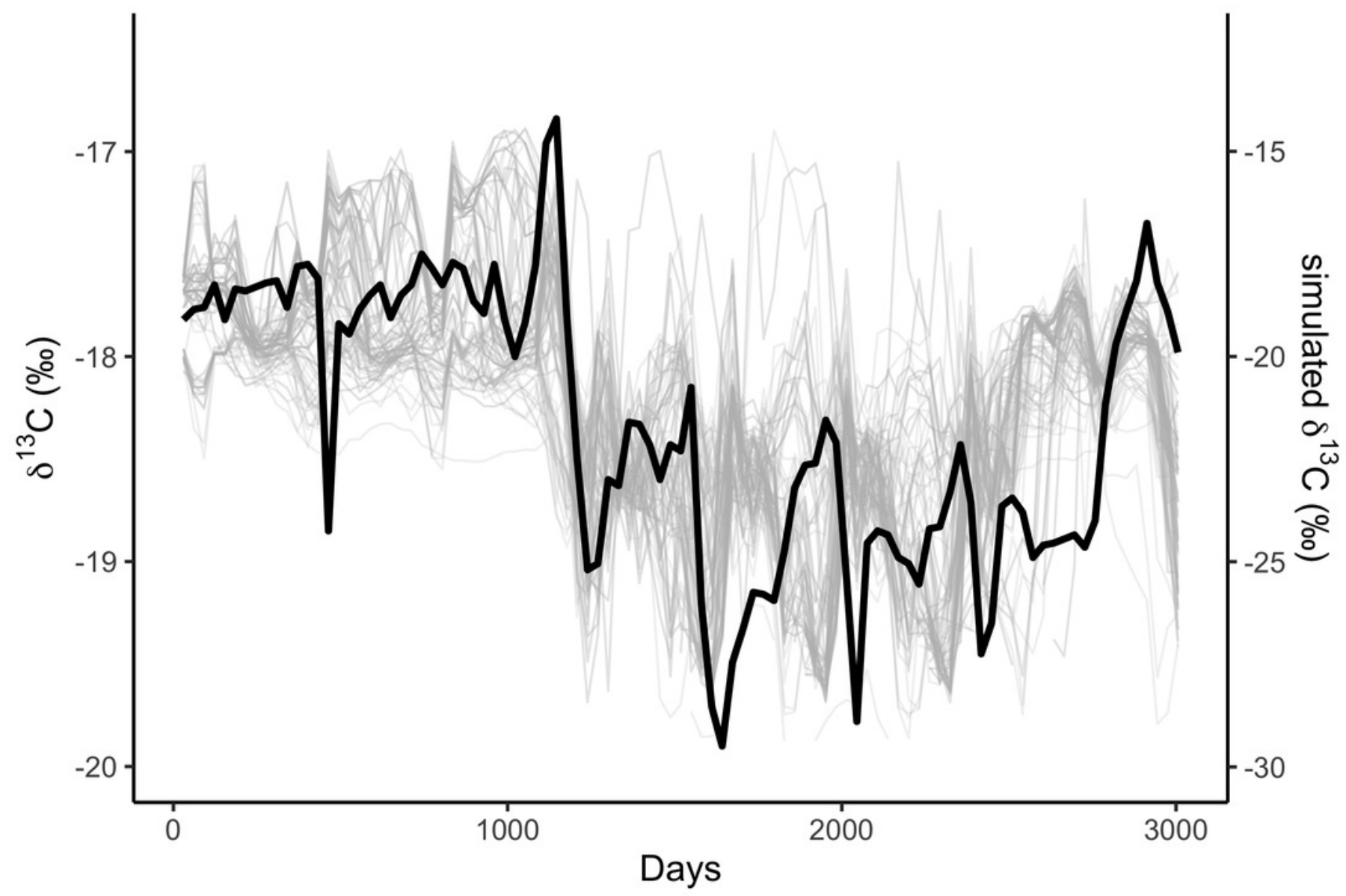




\section{Figure 2}

Variation in stable isotope values in the NHM blue whale, expressed as $\mathrm{d} 13 \mathrm{C}$ and $\mathrm{d} 15 \mathrm{~N}$.

Variation in stable isotope values in the NHM blue whale, expressed as d13C (black circles, left $\mathrm{y}$-axis) and $\mathrm{d} 15 \mathrm{~N}$ (grey circles, right $\mathrm{y}$-axis). Samples were taken longitudinally through the baleen plate ( $n=97$ samples from a single baleen plate for both isotopes). There is strong annual periodicity and cross-correlation (Figures S2 and S5) in both isotopes. The approximate relationship to years assuming a growth rate of $13.5 \mathrm{cmy}^{-1}$ is shown on the upper $x$-axis, and year boundaries are indicated by vertical dotted grey lines. Phases are the three behavioural phases defined in the text.

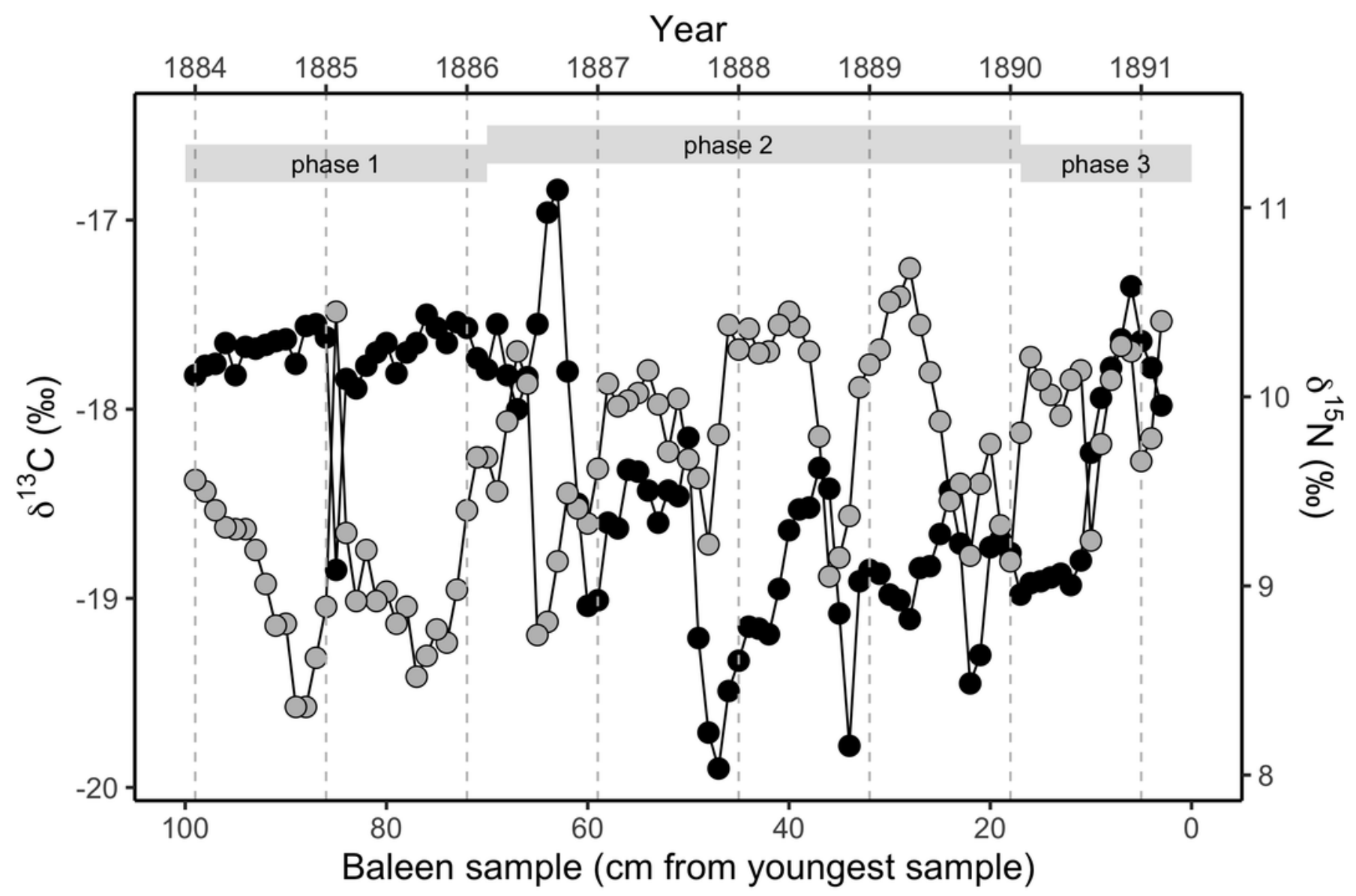


Figure 3

Simulated locations of the whale taken from the top $10 \%$ best fitting migratory movement models.

Colours reflect the behavioural phase. Phase one is early 1884 to spring 1886 , phase two is summer 1886 to spring 1890, and phase three is spring 1890 to spring 1891. 


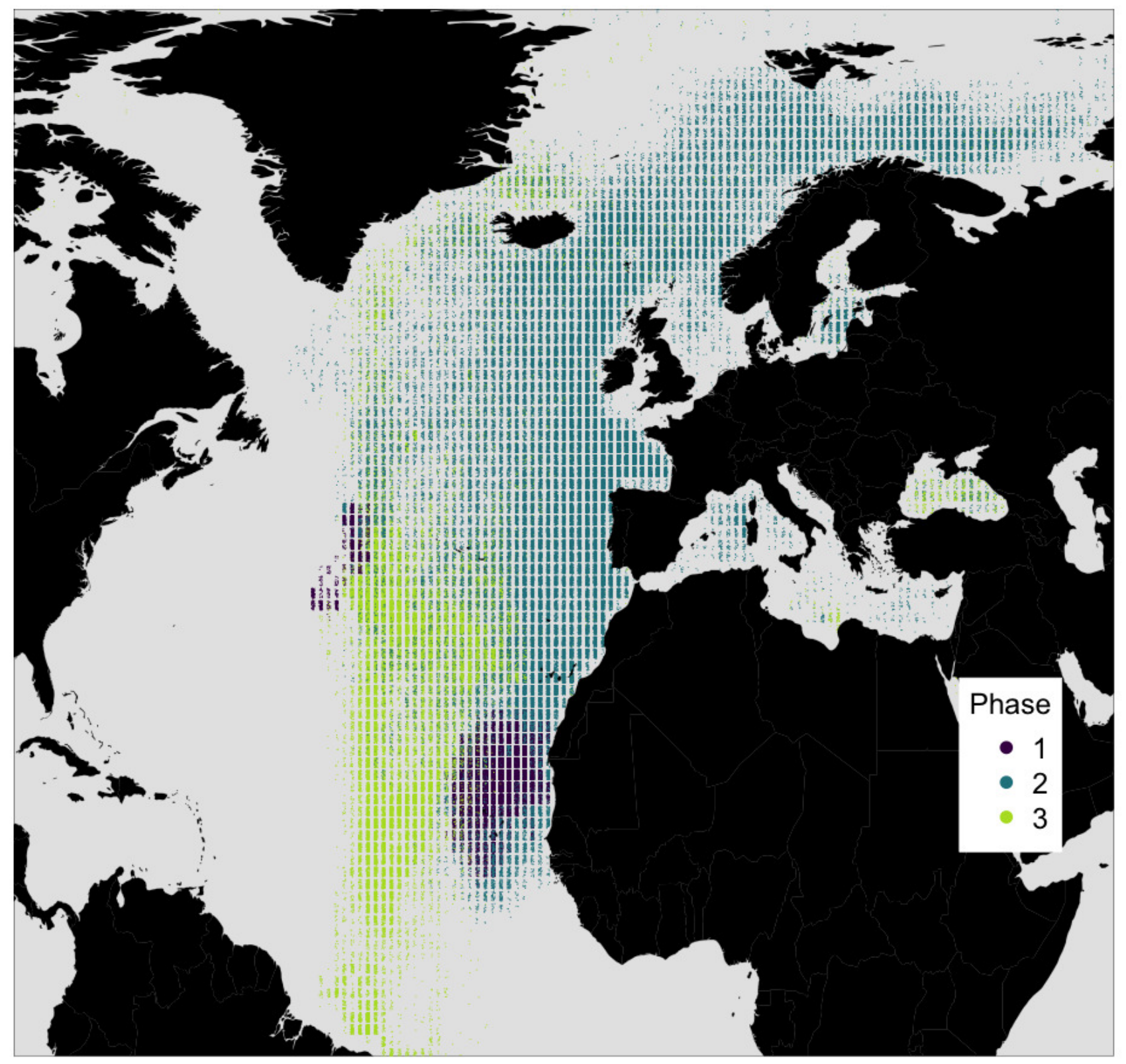




\section{Figure 4}

Simulated locations by month taken from the top $10 \%$ best fitting migratory movement models for behavioural phase two (summer 1886 to spring 1890) only.
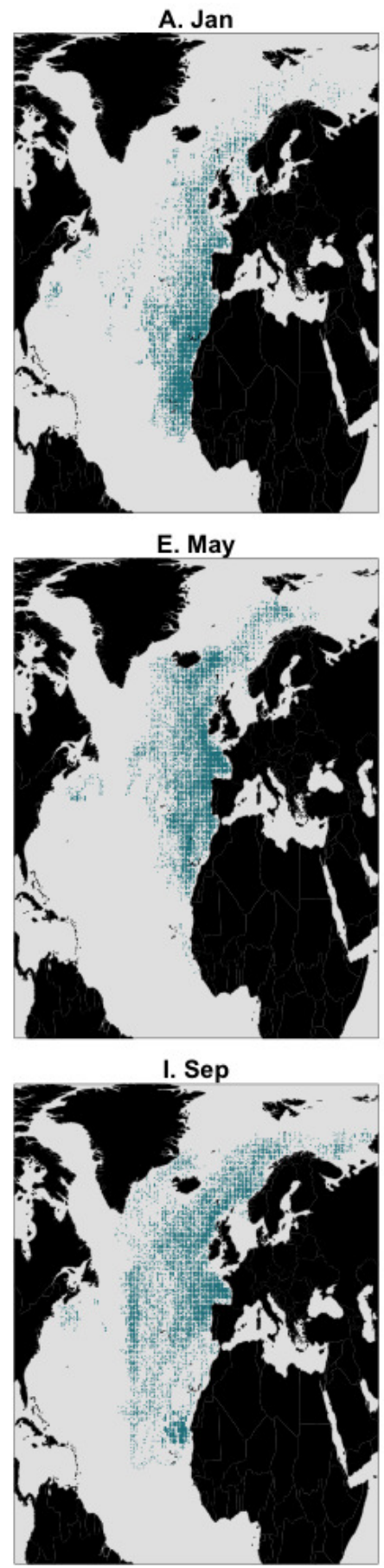

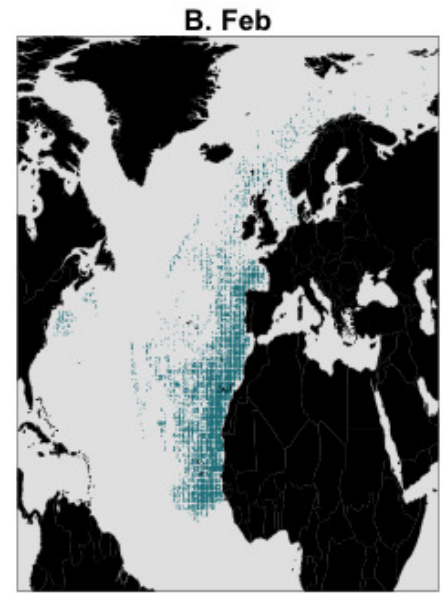

F. Jun

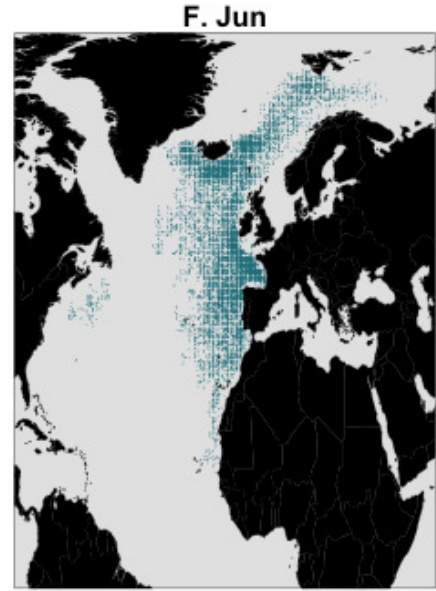

J. Oct

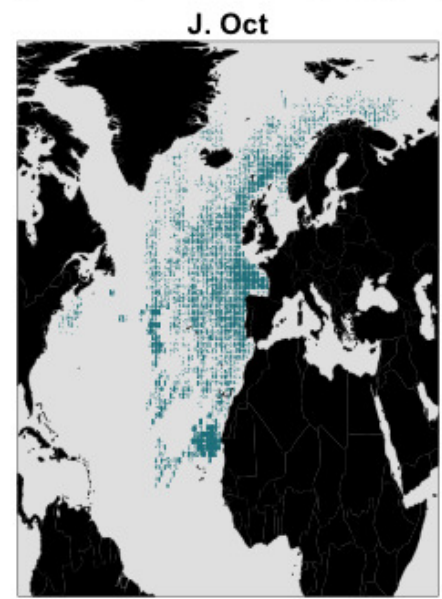

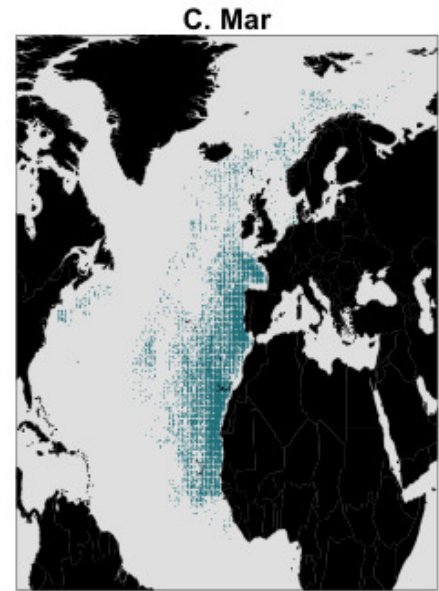

G. Jul

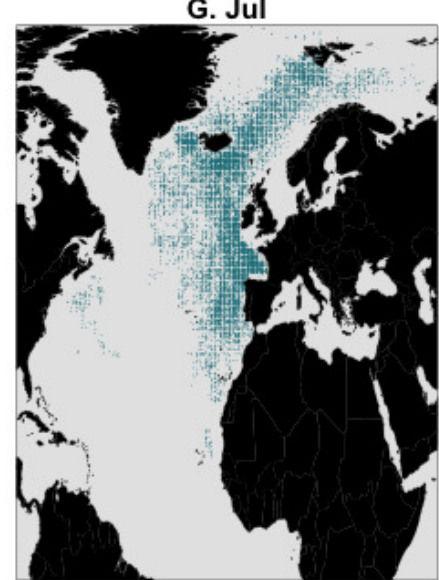

K. Nov

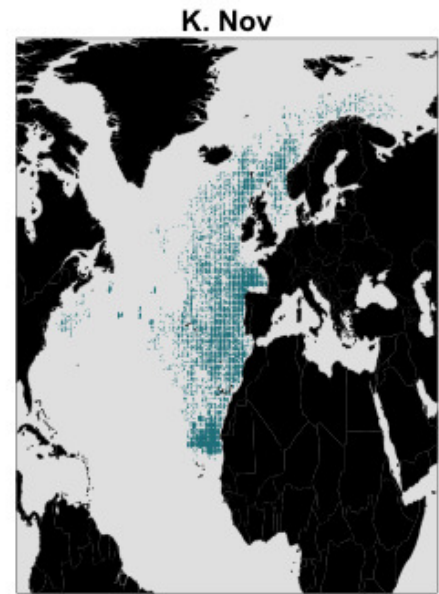

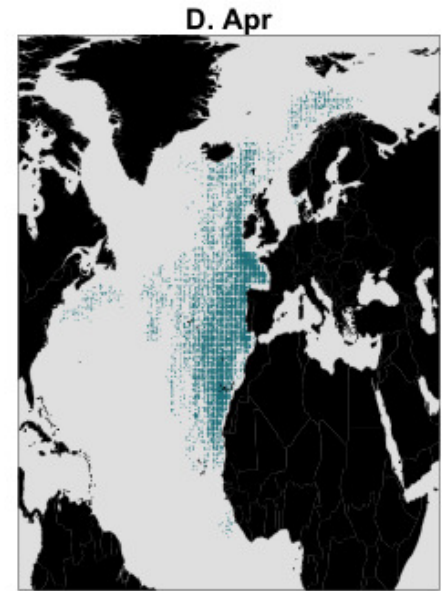

H. Aug

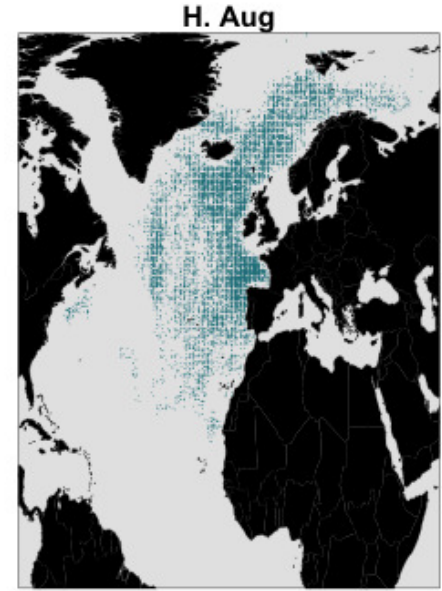

L. Dec

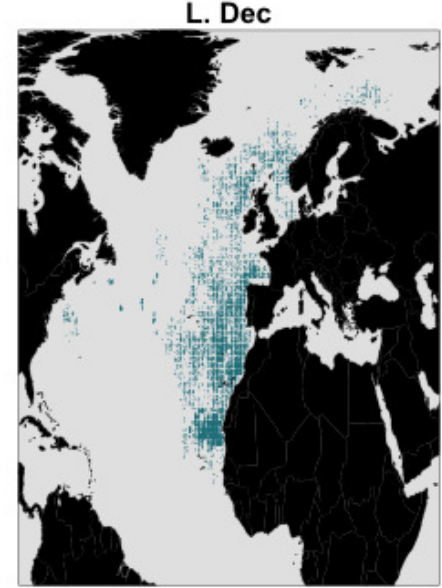

